\title{
Girih for Domes: Analysis of Three Iranian Domes
}

\author{
Mohammad Hossein Kasraei ${ }^{1}$ - Yahya Nourian ${ }^{1}$. \\ Mohammadjavad Mahdavinejad ${ }^{2}$
}

\begin{abstract}
Drawing Girih is a challenging mathematical and geometrical principle for artists and artisans in the present and past. This paper is to determine how Girih have been embedded on curved surfaces such as dome, according to their curvature. For achieving this goal, the Dast-Gardan pattern is represented as a prominent and complex type. This pattern enables the designer to use diverse types of star polygons in one pattern depending on the curvature of the surface. The research hypothesis is examined by analyzing the patterns of three historic domes in Iran. The result shows that there is a relationship between the number of points of star polygons and the change of the dome curvature.
\end{abstract}

Keywords Girih · Geometric pattern · Geometry · Dome - Curvature - Iranian art · Islamic art

\section{Introduction}

The rise and spread of Islamic art, during many consecutive years, has provided a great heritage of geometric patterns in art and architecture. The variety of geometric patterns employed by artists to embellish a wide range of works of art, including textiles, ceramics, metalwork, and architectural elements including Kar-bandi,

Mohammad Hossein Kasraei

Mh.kasraei@gmail.com

Yahya Nourian

yahya.nourian@gmail.com

Mohammadjavad Mahdavinejad

mahdavinejad@modares.ac.ir

1 5O7Studio, Tehran, Iran

2 Department of Art and Architecture, Tarbiat Modares University, Tehran, Iran 


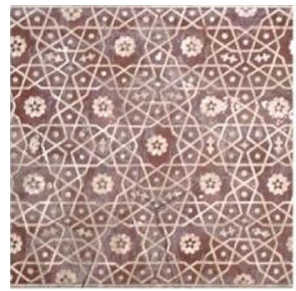

A

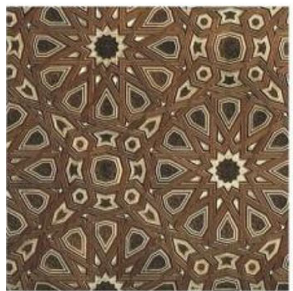

$\mathbf{E}$

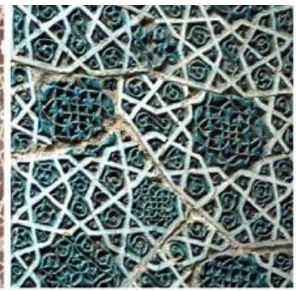

B

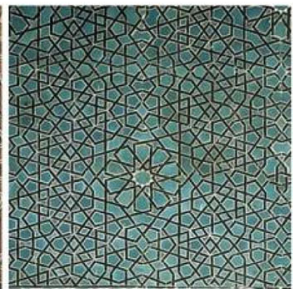

$\mathbf{F}$

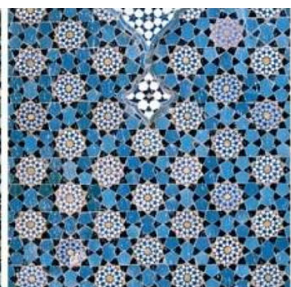

C

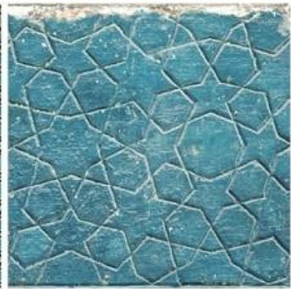

G

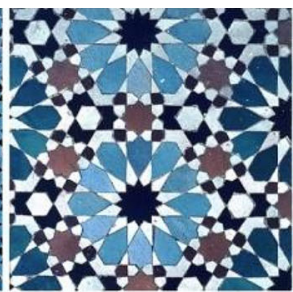

D

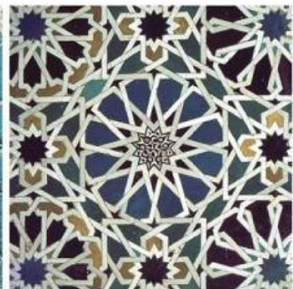

$\mathbf{H}$

Fig. 1 a Humayun's Tomb, Delhi; b Shakh-i-Zindeh complex, Samarkand; c Masjid-i-Jami, Isfahan; d Bou Inaniya Medersa. Fez; e al-Nasir Mosque, Cairo; f Karatay Medrese, Konya; g Altun Bogha Mosque, Aleppo; h Alhambra, Granada (Pattern in Islamic art 2015)

Rasmi-bandi, Muqarnas, and Girih. The tiling design (Fig. 1), called Girih ${ }^{1}$ in Persian, is one of the most significant and complicated techniques using geometric patterns to adorn art and architectural surfaces. The use of these geometric patterns spread across the world, from west India to Southern Europe and Turkey to the Arabian Peninsula. However, some believe the mathematics and construction of them originated in Iran (Necipoğlu and Al-Asad 1995).

Although these tessellations consist of some restricted and regular shapes (motifs) which have their own specific Persian names such as Shamseh (star), Torange (the quadrilateral tile), Sormeh-Dan (the bow tie tile), Tab'l (the concave octagonal tile), etc., these shapes have generated various and distinct patterns in art and architecture. (Ra'eesZadeh and Mofid 2011: 142).

Assessing many examples from the past 1000 years reveals that the main feature of the Girih is the mathematical and geometrical principles used in drawing it (Figure 2). The diversity of pattern types is based on the variety of methods for drawing. It is useful for current designers to know how each pattern is drawn.

In recent years, many efforts have been made to analyze the process of drawing Girih. Some recent research reveals the geometric order and reinvent drawing instructions for Girih, (Bonner 2003, Kaplan 2000, El-Said and Parman 1976). In contrast, others pursue traditional methods and study documents like scrolls, booklets etc., enabling active professional artisans to redefine original methods (Sarhangi 2012, Bodner 2012, Ra'eesZadeh and Mofid 2011). It seems that

\footnotetext{
${ }^{1}$ In this paper, we prefer to use Girih instead of Islamic pattern which used in many new books and articles, because Islamic pattern is a vague term that consists of many geometric and non-geometric patterns.
} 

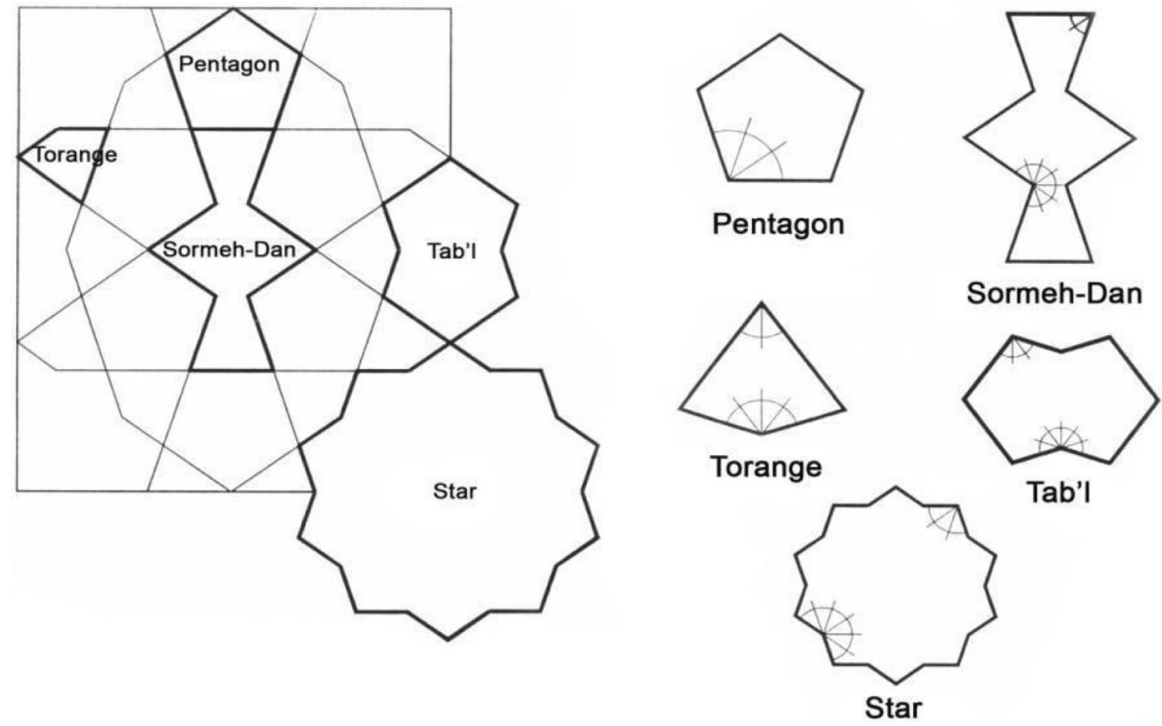

Fig. 2 Some regular shapes (motifs) which commonly are constructed Islamic patterns

achieving a comprehensive theory covering variety of Girih types will require more effort in the future. Previous research might be summarized in two major drawing approaches: Radial Grid approach and polygons in Contact approach.

The Radial Girih approach is a traditional method illustrated in many ancient documents such as "On Interlocking Similar or Corresponding Figures"(Fi tadakhul al-ashkal al-mutashabihat aw al-mutawafiqa) was written by Abu Ishaq Ibn Abdullah Koubnani which was attached to the "A Book on Those Geometric Constructions Which Are Necessary for a Craftsman"(Kitāb fī mā yaḥtāj ilayh alșāni' min al-a 'māl al-handasia) was written by Abu al-Wafa' al-Būzjān̄ī (10 June 940-15 July 998). The translation of this book represented in "Applied Geometry" (Jazbi 1997). This method was also taught by some Iranian professional artisans who inherited their profession from their ancestors dating back several centuries ago. These include Hussein Lorzadeh (Ra'eesZadeh and Mofid 2011), Mahmoud Maheronnaqsh (1984), Asghar Shaarbaf (1385), etc. In this approach, drawing the Girih begins by placing the centers of stars in a specific distance from each other. Depending on the number of star polygons, specific numbers of rays emanate from the center of stars. The intersections of these rays provide interstitial space which fills by different methods and creates various designs. In some medieval samples, a pattern covers a simple large surface by repeating and replicating a basic part of patterns called the repeat unit. ${ }^{2}$ In these simplified cases, the boundary of the repeat unit is constructed according to geometrical principles and the measurement of the center of each star in the corners of the repeat unit's boundary (Sarhangi 2012: 167). This basic unit consists of fundamental information about the Girih such as the

\footnotetext{
${ }^{2}$ A sample introduced step-by-step procedure for generating a typical Girih by this approach is described in (Sarhangi 2012).
} 

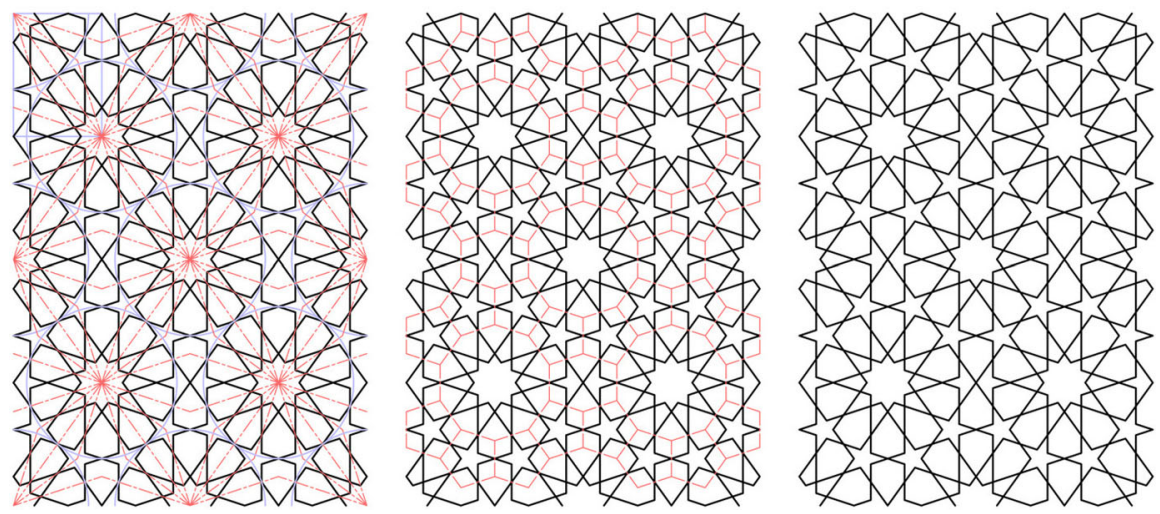

Fig. 3 Drawing one specific Girih presented in (Ra'eesZadeh and Mofid 2011) (R). Drawn via the Polygons in Contact approach (M). Drawn via the Radial Grid approach (L). Drawn by authors

number of points of star polygons, the placement and the distance between the centers of each star polygon. Many of these repeat units have been found in specific resources such as preserved Topkapi and Tashkent scrolls. Some researchers (Necipoğlu and Al-Asad 1995: 10-12) believe that the repeat unit drawings of these architectural scrolls most likely served as an aid to memorization for architects and master builders.

The Polygons in Contact approach is the another method, articulated by E. H. Hankin in the early part of the twentieth century (Hankin 1925). In this method, a surface covered with a network consists of "polygons in contact" (Kaplan 2005: 177-180) which is an unbounded and infinite pattern, and it might be resized in order to fit a surface. Using the polygons in contact approach leads to regular and primitive patterns and, therefore, could not generate all the traditional types of Girih.

Investigating and comparing these two identified methods reveals that the Radial Grid approach is a general method that could generate a wide range of varied Girih, from traditional to new ones, and the Polygons in the Contact approach is just a specific and restricted type which has constant and equal distance between each center of stars (Fig. 3).

This notion can be explained when we observe specific kinds of traditional Girih which are difficult or impossible to be drawn via the Polygons in Contact approach. For example, in traditional documents, there is a developed and elegant type of Girih called "Dast-Gardan"3 in Persian (Fig. 4).

The Dast-Gardan Girih is a developed kind of traditional Girih that consists of diverse types of stars fixed in different distances intentionally by the designer. The interstitial space among star polygons then fills geometrically by basic regular shapes (motifs) such as Torange, Sormeh-Dan, Tab'l, etc. Recently, some

\footnotetext{
3 Dast-Gardan is a Persian term that consists of two words; "Dast" is a noun which means "hand" and "Gardan" is a verb means "circulate". Iranian professional artisans used this term because Dast-Gardan patterns could be drawn freely according to the artisan's decision.
} 

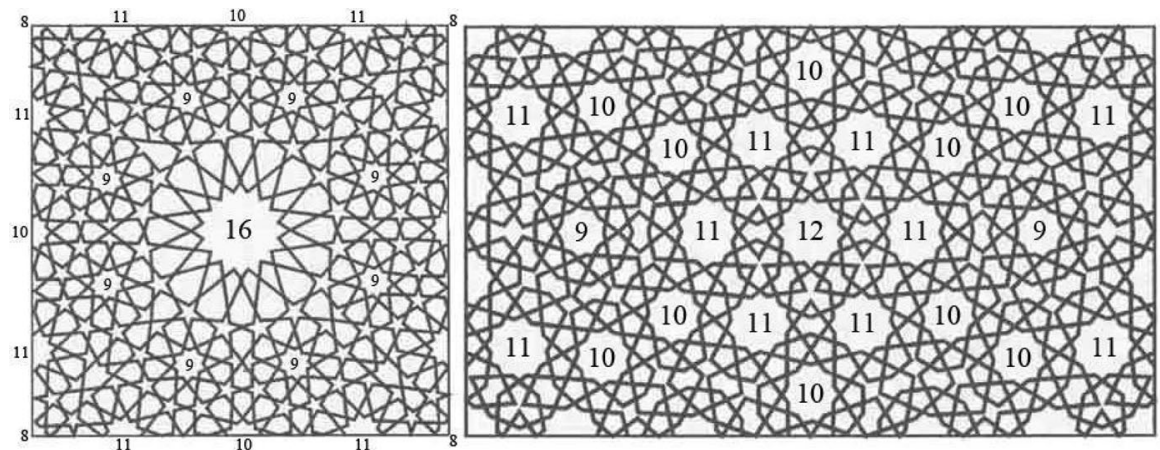

Fig. 4 Two samples of Dast-Gardan pattern with various types of star polygons; (L) has 8, 9, 10, 11, 16 pointed star polygons, (R) has 9, 10, 11, 12 pointed star polygons. Designed by Hussein Lorzadeh (Ra'eesZadeh and Mofid 2011: 178)

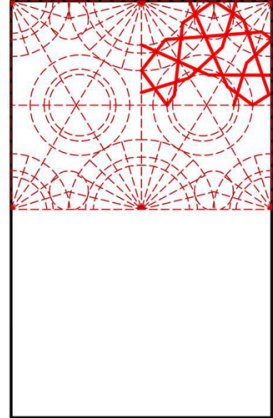

A

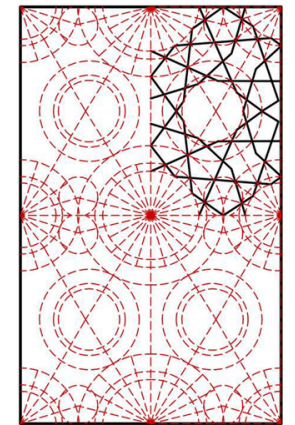

B

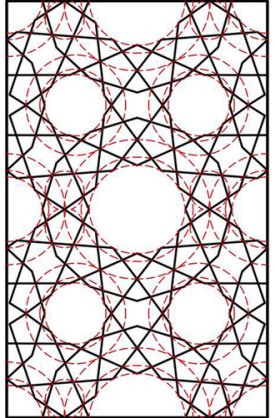

C

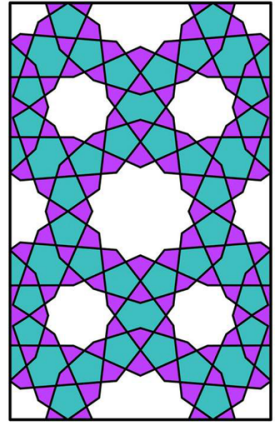

D

Fig. 5 Redrawing a Dast-Gardan Girih designed by Hussein Lorzadeh (Ra'eesZadeh and Mofid 2011: 181). Fixing the center of circles with diverse diameters and drawing rays emanate from the centers (a); constructing the fundamental region (b); Drawing Girih unit (c); Drawing the complete Girih (d)

researchers have attempted to reinvent a method to draw Dast-Gardan Girih. B. Lynn Bodner (2011) presented a method to draw a nine- and twelve-pointed star polygon design found in Tashkent scrolls. Although she did not mention anything about the Dast-Gardan concept and did not achieve a comprehensive method which covers the wide range of Dast-Gardan Girih; she outlines a method to fill in the interstitial space with the irregularly shaped pentagonal star, hexagons and arrowlike shapes. Generally drawing Dast-Gardan Girih commances with fixing the center of diverse circles with various diameters. Then the circles divide to some congruent angles by creating rays that emanate from the center of circles. These rays intersect and then construct the fundamental region for the tiling which consists of different types of star polygons. Figure 5 is an example for a step-by-step construction of a Dast-Gardan Girih designed by Hussein Lorzadeh (Ra'eesZadeh and Mofid 2011).

Unlike common Girih drawn with regard to an interactive basic unit and on an infinite surface, Dast-Gardan is constructed based on the form and shape of the 
surface. In other words, this type of Girih design is dependent on the surface, so the measurements and shape of the surface alter the process of its design. Dast-Gardan patterns have been utilized to impose geometric order on complicated surfaces and to have various options in order to draw a unique pattern. The role of Dast-Gardan becomes evident when a designer intends to draw a pattern on a curved surface.

\section{Girih for Curved Surfaces}

Professional Iranian artisans succeeded wonderfully in drawing patterns on curved surfaces and in making them fit the surface. A dome is one of the most significant curved surfaces and serves as a main characteristic of Islamic architecture and adoring domes is one of the challenging practice for Iranian artisans. A dome can be thought of as an arch which has been rotated around its central vertical axis and can therefore be categorized by its initial arch. However, many different types of arches are found in Islamic architecture throughout the medieval period. For example, a four-centered arch is a well-known arch utilized to shape many domes. The structure of a four-centered arch is achieved by drafting two arcs which rise steeply from each springing point ${ }^{4}$ on a small radius and then turn into two arches with a wide radius and much lower springing point. A dome made by a four-centered arch can be considered a smooth surface which has positive Gaussian curvature ${ }^{5}(\mathrm{~K}>0)$. As the Gaussian curvature is the product of the two principal curvatures $\left(K=\mathrm{k}_{1} \mathrm{k}_{2}\right)$, a dome-type surface at each point on a vertical section has unique Gaussian curvature (Fig. 6).

On the other hand, according to historic documents, drawing Girih on the interior and exterior surface of a dome was a prominent challenge that many artisans faced (Hankin 1925: 23). The challenge is that patterns suitable to embed on the surface of domes do not follow the conventional methods of drawing and require a different approach (Fig. 7).

No comprehensive study exists about drawing Girih on domes, but similar topics have been studied in recent research that attempts to draw patterns on a nonflattened surface. Kaplan and Salesin (Kaplan and Salesin 2004) present a method to embed a specific pattern on different Euclidean and non-Euclidean surfaces. They state that "the structure of star patterns reflects the curvature of the space in which it is embedded" (Kaplan and Salesin 2004: 111). Consequently, the star polygons of a specific pattern change when placed on different surfaces with different curvatures. In other words, it may be concluded that the number of points of star polygons in Islamic patterns depends on the measurement of the "amount of space" (Kaplan and Salesin 2004: 111) around each point. Below we try to determine whether Kaplan and Salesin's conclusion could relate to Islamic patterns drawn by traditional artisans which decorated the surface of domes in Islamic architecture.

\footnotetext{
4 The point from which an arch and vaults springs or rises from its supports.

5 Because the curvature is the same way in two mutually perpendicular directions.
} 


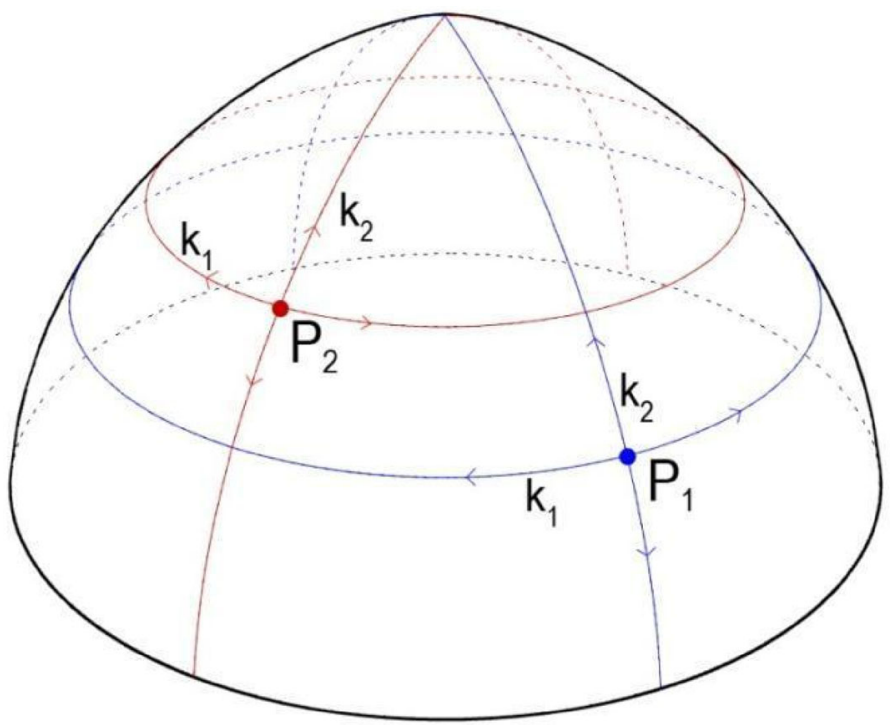

Fig. 6 The Gaussian curvature $(\mathrm{K}=k 1 k 2)$ at point1. $(P 1)$ is different from point $2(P 2)$
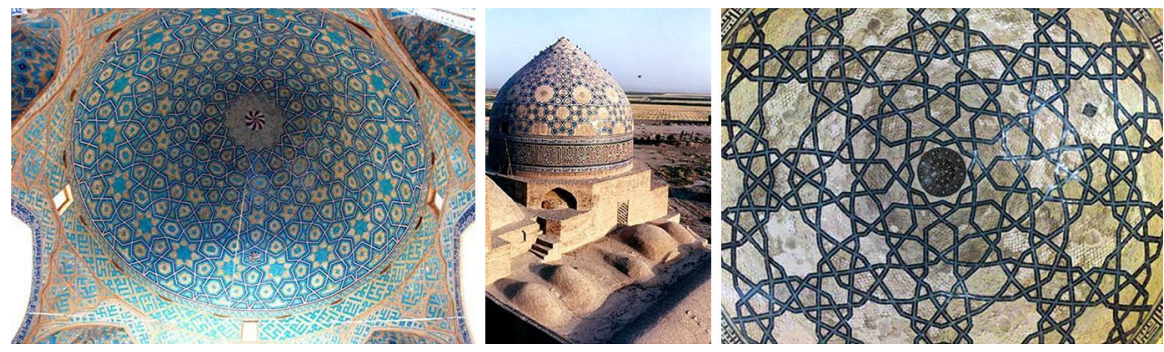

Fig. 7 (L) the interior dome of Yazd Jame' Mosque,(M) the exterior dome of Saveh Jame' Mosque, (R) the interior dome of Saveh Jame' Mosque. Photographed by authors

\section{Analysis}

Assessing the curved surfaces in Islamic architecture reveals that the Islamic patterns drawn on domes were usually designed by the Dast-Gardan method. This is not surprising, given the relationship between star polygons and the curvature of a surface. Based on the previous section, making a change in the number of star polygons applied to the pattern depends on the change of the dome curvature. So the pattern drawn on a dome should consist of diverse types of star polygons. This means the patterns should be designed by the Dast-Gardan method. This can be confirmed by investigating the geometry of three scarce and special type of traditional domes in Iran and other Islamic region which covered by sophisticated and elegant Dast-Gardan Girih. 

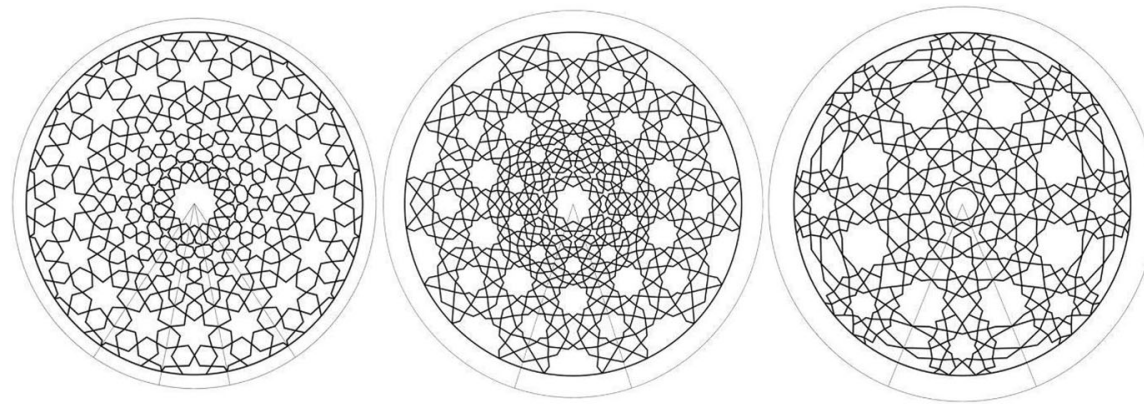

Fig. 8 (L) Girih on the interior dome of Yazd Jame' Mosque, (M) Girih on the exterior dome of Saveh Jame' Mosque, (R) Girih on the interior dome of Saveh Jame' Mosque. Drawn by authors

These three domes are the Yazd Jame' Mosque's dome, interior and exterior domes of Saveh Jame' Mosque which belong to two prominent and well-known buildings in Islamic architecture. Evidence suggests that the Saveh Jame' Mosque was constructed in 504 AH during the Muhammad-ibn-Malek Shah Saljuqi period coinciding with the development of the city. Around the fourth or fifth century, the dome was constructed in the mosque's south front. The dome of Saveh Jame' Mosque measures $14 \mathrm{~m}$ in diameter and $17 \mathrm{~m}$ high and is covered in Iranian Moaragh tessellations. The other building is Yazd Jame' Mosque which dates back to the Timurid dynasty, about 861 AH. The double-shelled dome of Yazd Jame' Mosque is regarded as one of the masterpieces of Islamic architecture because of its geometry and patterns. These three domes have been selected due to the differences in their curvature so that the following discussion can represent the fact that the change in the curvature of the domes has a specific relation with the change in the Dast-Gardan Girih (Fig. 8).

Investigating Dast-Gardan Girih drawn on domes shows that there is a significant relationship between the curvature of domes' surfaces and the construction of Girih. For example the Fig. 9 shows that the curvature of the surface of a dome changing from the spring point to the apex corresponds with the change in number of points of star polygons in remarkable stages. Decreasing the curvature of a dome's surface leads to decreasing the number of points of star polygons.

Figure 10 shows the change in the Gaussian curvature of these three domes and the placement and number of points of each star polygon on the domes. Analyzing the Dast-Gardan patterns on these three domes reveals that the changing curvature is not the same in different cases. So the pattern which belongs to each dome has its own number of points of star polygons. For example, the curvature of the exterior dome of the Saveh Jame' Mosque (Fig. 10c) changes significantly in three stages from base to apex. In its interior dome, the curvature changes in two stages. In contrast, the Yazd Jame' Mosque's dome is similar to a hemisphere, so the change in curvature is not great, and changes in one stage. Based on our assessment, changing curvature and the number of points of star polygons have a meaningful 


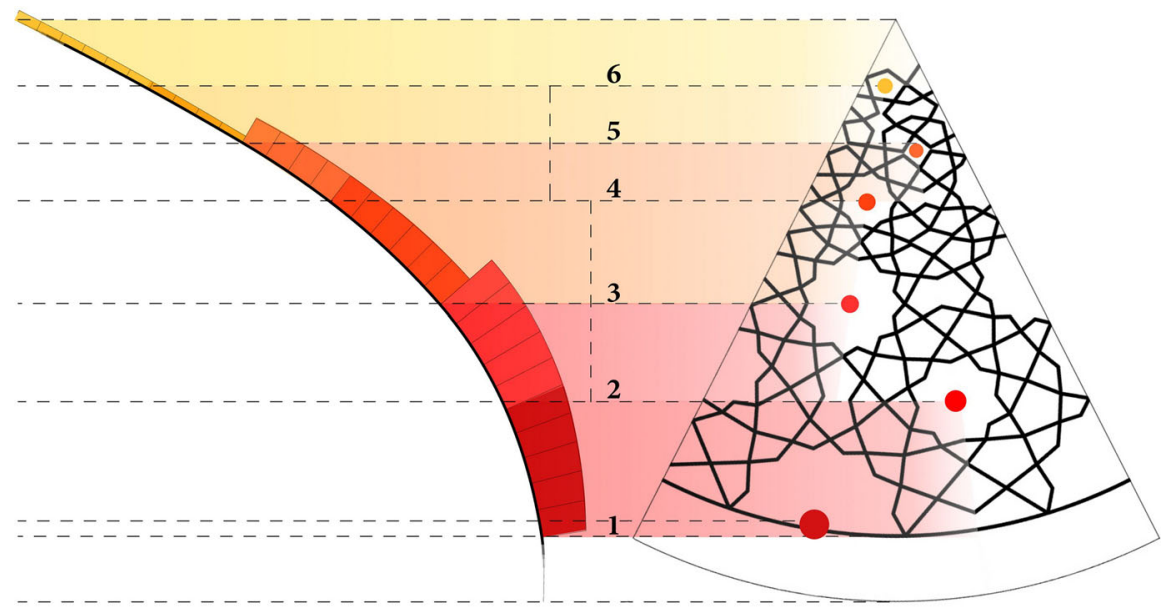

Fig. 9 This diagram shows that the changing in curvature of a dome's surface corresponds with the change in number of points of star polygons. The diagram is a section of the exterior dome of Saveh Jame' Mosque in Iran. Drawn by authors

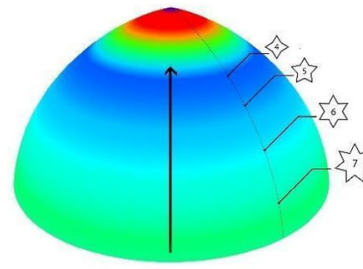

A

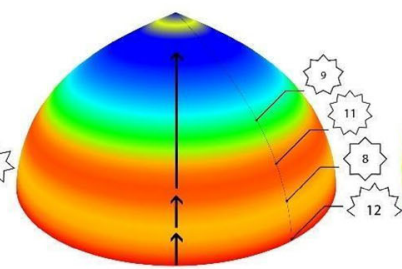

C

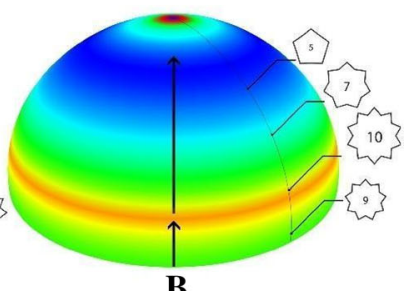

B

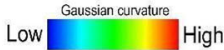

Fig. 10 This diagram shows that the Gaussian curvature and pattern of a Yazd Jame' Mosque's dome, b interior domes of Saveh Jame' Mosque, c exterior domes of Saveh Jame' Mosque. (The diagram was drawn via Rhinoceros 5 by the authors)

relationship. For instance, the pattern on the interior dome of Yazd Jame' Mosque has four different star polygons- 7, 6, 5, 4-that relate to the changing curvature. Based on Fig. 10a, the number of points of the star polygons increases steadily from 4 to 7. The patterns on the interior and exterior dome of Saveh Jame' Mosque have a different trend. The changing curvature on the interior dome of Saveh Jame' Mosque jumps in one stage and its number of points of star polygons increases from 9 to 10 and then decreases to 7 and 5. The changing curvature on the interior dome of the Saveh Jame' Mosque jumps in two stages. As seen in Fig. 10c, first the number of points of star polygons goes down from 12 to 8 , then goes up to 11, and finally decreases. 


\section{Conclusion}

The variety of methods for drawing Islamic patterns leads us to one of the significant types, called Dast-Gardan in Persian. The importance of Dast-Gardan is evident when designers try to draw a pattern on a curved-surface. A dome is one of the most significant curved surfaces, which has different Gaussian curvature at each point. The number of points of star polygons in Islamic patterns depends on the curvature of the surface; hence the pattern embedded on a dome should consist of diverse types of star polygons. So the patterns on a dome should be a Dast-Gardan pattern in which its star polygons change according to the curvature of its surface. Analyzing the patterns of three traditional domes shows that there is a direct relationship between the changing curvature and the type and number of points of star polygons. As curvature increases throughout the surface, the pattern accommodates stars with larger numbers of points.

\section{References}

Jazbi, S. A. 1997. Applied Geometry. Soroush Press (in Farsi).

Bodner, B. L. 2011. A Nine- and Twelve-Pointed Star Polygon Design of the Tashkent Scrolls. Proceedings of Bridges 2011: Mathematics, Art, Architecture, Music, Culture, Conference 2011, Reza Sarhangi and Carlo Séquin, eds., pp. 147-154. Phoenix: Tesselations Publishing. http:// archive.bridgesmathart.org/2011/bridges2011-147.pdf.

Bodner, B. L. 2012. The Topkap1 Scroll's Thirteen-Pointed Star Polygon Design. Proceedings of Bridges 2012: Mathematics, Music, Art, Architecture, Culture, Robert Bosch, Douglas McKenna and Reza Sarhangi, eds., pp. 157-164. Phoenix: Tesselations Publishers. http://archive.bridgesmathart.org/ 2012/bridges2012-157.pdf.

Bonner, J. 2003. Three traditions of self-similarity in fourteenth and fifteenth century Islamic geometric ornament. In Meeting Alhambra, ISAMA-BRIDGES Conference Proceedings, Javier Barrallo, et al., eds., pp. 1-12. Granada: University of Granada. http://archive.bridgesmathart.org/2003/bridges20031.pdf.

El-Said, I. and A. Parman, A. 1976. Geometrical Concepts in Islamic Art. London: World of Islam Festival Publ. Co.

Hankin, E. H. 1925. The Drawing of Geometric Patterns in Saracenic Art, vol. 15. Archaeological Survey of India.

Kaplan, C. S. 2005. Islamic star patterns from polygons in contact. Proceedings of Graphics Interface 2005, pp. 177-185. Canadian Human-Computer Communications Society.

Kaplan, C. S. 2000. Computer Generated Islamic Star Patterns. Bridges: Mathematical Connections in Art, Music, and Science, Conference Proceedings 2000, Reza Sarhangi, ed., pp. 105-112. http:// archive.bridgesmathart.org/2000/bridges2000-105.html.

Kaplan, C. S., and D. H. Salesin. 2004. Islamic star patterns in absolute geometry. ACM Transactions on Graphics (TOG) 23(2): 97-119.

Maheronnaqsh, M. 1984. Design and Execution in Persian Ceramics. Tehran: Reza Abbasi Museum Press.

Ra'eesZādeh, M., and H. Mofid. 2011. Ehyā-ye Honar Hā-ye Az Yād Rafteh: Mabāni-ye Me'māri-ye Sonati Dar Iran Be Revāyat-e Ostād Hossein-e Lorzādeh (Revival Of Forgotten Arts: Basics Of Traditional Architecture In Iran As Narrated By Master Hossein-E Lorzadeh). Tehran: Enteshārāt-e Moulā (Moula Publications) (in Farsi).

Necipoğlu, G., and Al-Asad, M. 1995. The Topkapı Scroll: Geometry and Ornament in Islamic Architecture. Topkapı Palace Museum Library MS H. 1956. Santa Monica, CA: Getty Center for the History of Art and the Humanities. 
Sarhangi, R. 2012. Polyhedral Modularity in a Special Class of Decagram Based Interlocking Star Polygons. Proceedings of Bridges 2012: Mathematics, Music, Art, Architecture, Culture, Robert Bosch, Douglas McKenna and Reza Sarhangi, eds., pp. 165-174. Phoenix: Tessellations Publishing. http://archive.bridgesmathart.org/2012/bridges2012-165.pdf.

Shaarbaf, A. 1385. Girih and Karbandi. Tehran: Sobhan Nour. (in Farsi).

Pattern in Islamic Art. 2015. http://patterninislamicart.com/ Accessed 20 February 2015.

Mohammad Hossein Kasraei received his undergraduate degree in architecture from Tehran Art University. He has taken master of architecture from Tehran Art University before working as a professional architect in Iran. He has managed and designed a full range of architectural projects, spanning from interior design to landscape from initial studies to detailing. His portfolio includes residential, cultural and religious buildings, as well as landscape. His research interests are in the area of Islamic architecture, computational design and fabrication. He founded 507studio in 2011 and has been working there as an architect and designer. He also founded Fablab.ir in 2014, a Tehran-Based digital fabrication laboratory, in order to provide an open access environment for design students.

Yahya Nourian is an Architect and a academic researcher who holds a Master of Architectural engineering from Tarbiat Modares University in Tehran and a Bachelor of Architecture from Tehran Art University. He has a broad range of professional skills in Architectural design and also has some academic papers focusing on history of art and architecture. He was previously a lecturer at Tehran Art University and some other universities in Iran. His research interests are in the area of Islamic architecture, art and architecture history, computational design and fabrication. He founded 5O7studio in 2011 and has been working there as an architect and manager. He also founded Fablab.ir in 2014, a Tehran-Based digital fabrication laboratory, in order to provide an open access environment for design students.

Mohammadjavad Mahdavinejad was born in Tehran, Iran, at 1977. His M.A. in architecture was finished at 2003 in Tehran University, Tehran, Iran. He earned Ph.D. in architecture at the same university by 2007 . His major fields of study are history of architecture and architectural technology. He is assistant professor of department of architecture; faculty of art and architecture, Tarbiat Modares University, Tehran, Iran. He is author of many published papers and book. His research interests are smart architecture and materials. 